\title{
BRPKM
}

Buletin Riset Psikologi dan Kesehatan Mental

http://e-journal.unair.ac.id/index.php/BRPKM

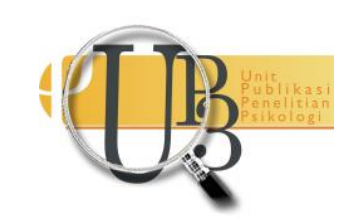

ARTIKEL PENELITIAN

\section{Pengaruh Job Insecurity dan Work Life Balance terhadap Stres Kerja pada Karyawan Outsourcing}

\author{
MOCHAMMAD RIZAL RAMDHAN \& FAJRIANTHI*
}

Departemen Psikologi Industri dan Organisasi Fakultas Psikologi Universitas Airlangga

\begin{abstract}
ABSTRAK
Stres kerja merupakan suatu permasalahan umum yang terjadi pada karyawan termasuk karyawan outsourcing. Penelitian ini bertujuan untuk mengetahui apakah terdapat pengaruh job insecurity dan work life balance terhadap stres kerja pada karyawan outsourcing. Penelitian ini menggunakan tipe penelitian kuantitatif terhadap 83 karyawan outsourcing di Indonesia. Instrumen penelitian menggunakan Job Insecurity Scale terdiri dari 4 aitem, Work Life Balance terdiri dari 17 aitem, dan Stres Kerja terdiri dari 9 aitem. Analisis data menggunakan teknik uji regresi linear berganda. Hasil penelitian menunjukkan nilai signifikansi job insecurity terhadap stres kerja sebesar 0,877, WIPL terhadap stres kerja 0,010, PLIW terhadap stres kerja 0,793, PLEW terhadap stres kerja 0,046, WEPL terhadap stres kerja sebesar 0,759. Sedangkan secara simultan nilai signifikansi job insecurity, WIPL, PLIW, PLEW, WEPL adalah 0,001 yang menunjukkan bahwa terdapat pengaruh yang signifikan antara job insecurity WIPL, PLIW, PLEW, WEPL terhadap stres kerja pada karyawan outsourcing.
\end{abstract}

Kata kunci: stres kerja, karyawan outsourcing

\begin{abstract}
Work stress is a common problem that occurs in employees, including outsourcing employees. This study aims to determine whether there is an effect of job insecurity and work life balance on work stress in outsourcing employees. This study uses a quantitative type of research on 83 outsourcing employees in Indonesia. The research instrument used the Job Insecurity Scale consisting of 4 items, Work Life Balance consisting of 17 items, and Job Stress consisting of 9 items. Data analysis using multiple linear regression test techniques. The results showed that the significance value of job insecurity for work stress was 0.877, WIPL for work stress was 0.010, PLIW for work stress was 0.793, PLEW for work stress was 0.046, WEPL for job stress was 0.759. Meanwhile, simultaneously the significance value of job insecurity, WIPL, PLIW, PLEW, WEPL is 0.001 which indicates that there is a significant influence between the job insecurity of WIPL, PLIW, PLEW, WEPL on work stress on outsourcing employees.
\end{abstract}

Keywords: outsourcing employees, work stress

Buletin Penelitian Psikologi dan Kesehatan Mental (BRPKM), 2021, Vol. 1(1), 327-337

*Alamat korespondensi: Fakultas Psikologi Universitas Airlangga, Kampus B Universitas Airlangga Jalan Airlangga 4-6 Surabaya 60286. Surel: fajrianthi@psikologi.unair.ac.id

Naskah ini merupakan naskah dengan akses terbuka dibawah ketentuan the Creative Common Attribution License (CC-BY-4.0) (http://creativecommons.org/licenses/by/4.0), 
sehingga penggunaan, distribusi, reproduksi dalam media apapun atas artikel ini tidak dibatasi, selama sumber aslinya disitir dengan baik.

\section{P E N D A H U L U A N}

Perusahaan ataupun sebuah organisasi selalu dituntut untuk peningkatan kinerja. Hal tersebut dilakukan untuk mencapai beberapa capaian yang telah ditargetkan organisasi. Salah satu bentuknya adalah memiliki sumber daya manusia yang optimal efektif dan efisien. Banyaknya tugas serta tuntutan pekerjaan yang diterima karyawan tentu membutuhkan tenaga bantuan dalam menyelesaikan sebagian tugas-tugasnya. Kini beberapa perusahaan telah banyak yang menggunakan jasa karyawan outsourcing. Namun tenaga alih daya (outsourcing) tidak memiliki status tetap sebagai karyawan, sehingga karyawan outsourcing dapat mengalami pemberhentian secara tiba-tiba dengan alasan tertentu.

Terdapat beberapa permasalahan stres kerja pada karyawan outsourcing. Data yang ditunjukkan pada penelitian Padma dkk (2015) tentang masalah kesehatan dan stres pada karyawan outsourcing sebagai berikut, skor stres yaitu sebanyak 56\% mengalami gejala muskuloskeletal, diantaranya 22\% baru didiagnosis hipertensi, 10\% menderita diabetes, 36\% mengalami dislipidemia, 54\% mengalami depresi, kecemasan dan insomnia, 40\% mengalami obesitas. Sebagian besar karyawan yang mengalami obesitas memiliki skor stres yang lebih tinggi (Padma dkk., 2015). Dalam penelitian Smith \& Smith (2017) kelompok pekerja (karyawan outsourcing) melaporkan adanya masalah kesehatan mental dan tingkat stres yang tinggi. Hal tersebut dipicu karena adanya faktor tuntutan pekerjaan dan kurangnya dukungan maupun kontrol diri (Smith \& Smith, 2017). Penelitian oleh Sari dkk meneliti tentang pengaruh stres kerja terhadap kinerja karyawan outsourcing. Hasilnya sebanyak 134 karyawan outsourcing 70,2\% diantaranya mengalami penurunan kinerja dan sebanyak 71,9\% diantaranya mengalami stres kerja yang tinggi. Hal ini menyatakan adanya stres yang dialami oleh karyawan outsourcing di tempat kerja. Namun, stres kerja yang dialami karyawan outsourcing tidak hanya disebabkan pekerjaan saja terdapat pengaruh-pengaruh lain seperti beban kerja yang tinggi, gaji yang rendah, konflik antar pribadi serta permasalahan keluarga yang kemudian terbawa dalam pekerjaan (Sari dkk., 2016).

Stres kerja sudah disepakati oleh banyak peneliti sebelumnya akan dapat mempengaruhi kinerja. Sehingga untuk dapat meningkatkan kinerja perlu untuk menurunkan stres kerja karyawan. Namun stres kerja ternyata tidak hanya menimbulkan dampak negatif saja melainkan memiliki dampak positif. Istilah stres yang memberikan dampak positif terhadap individu disebut eustres, sedangkan yang mengakibatkan dampak negatif disebut distress (Gadzella dkk., 2012). Hal ini juga telah dijelaskan pada kurva Yerkes-Dodson yang memperlihatkan kurva perbedaaan antara distress dan eustress. Stres yang memiliki dampak positif pada kinerja dan kesehatan adalah stres yang tidak melampaui batas maksimal. Sedangkan stres yang berdampak negatif adalah saat stres yang telah melebihi kurva atau batas maksimal (Le Fevre dkk., 2003). Sehingga fenomena stres tidak selalu merugikan karena dalam kenyataannya stres pada tingkat tertentu adalah suatu proses yang harus dilalui individu untuk mencapai target tertentu. Meskipun baru-baru ini istilah eustress dan distress pada beberapa literatur ilmiah adalah bergantung pada persepsi dan kognisi individu yang merasakannya (Bienertova-Vasku dkk., 2020).

Meski demikian faktanya masih banyak terdapat stres kerja yang memiliki dampak negatif. Pada tahun 1996 World Health Organization (WHO) menyatakan bahwa stres sebagai epidemi dunia pada abad 21 lalu. American Institute of Stress juga telah menyebutkan data stres kerja yang berada di sebagian negara seperti Amerika Serikat sebanyak 83\% menderita stres terkait pekerjaan. Hasil survei Regus 2012 dalam lingkup Asia Pasifik stres kerja di Indonesia mencapai 73\%. Hal ini setara dengan negara Cina

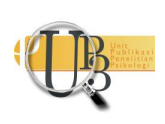


dan di bawah negara Thailand yang jumlahnya mencapai 75\%. Dari tahun sebelumnya Indonesia mendapati sebuah kenaikan sebanyak 9\% yang sebelumnya 64\% Timah (dalam Habibi \& Jefri, 2018). Tidak bisa dipungkiri bahwa stres kerja merupakan masalah kesehatan yang cukup banyak dialami oleh karyawan atau pekerja. Definisi dari stres kerja sendiri adalah ketika tuntutan pekerjaan yang dirasakan individu melebihi kemampuan untuk dapat memenuhi tuntutan tersebut sehingga menimbulkan rasa ketidaknyamanan psikologis (De Bruin, 2006).

Beberapa dampak dari stres kerja yang telah dirangkum pada beberapa kajian antara lain adalah adalah sebuah sikap emosional yang membahagiakan dan mencintai pekerjaannya (Hoboubi dkk., 2017). Dampak lain yang ditimbulkan dari stres kerja antara lain turnover intention. Angka yang cukup tinggi untuk turnover intention ditunjukkan di negara China pada sebuah penelitian oleh Liu dan Onwuegbuzie bahwa terdapat sebanyak 40,4\% karyawan melaporkan ingin meninggalkan profesinya disebabkan stres yang mereka alami (Liu \& Onwuegbuzie, 2012).

Terdapat beberapa penyebab karyawan merasakan stres kerja. De bruin \& Taylor (2005) menyatakan adanya pengaruh dari keamanan kerja (job security). Job security adalah harapan karyawan mengenai keberlangsungan dalam pekerjaannya seperti promosi, kesempatan karir serta kepastian (De Bruin \& Taylor, 2005). Sedangkan konsep job insecurity yaitu perasaan subjektif yang dirasakan dalam kemungkinan kedepan yang tidak diinginkan mengenai kondisi atau perkembangan karirnya yang mengakibatkan muncul respon berupa kekhawatiran, ketakutan, mengenai kehilangan pekerjaan (De Witte, 2005). Artinya apabila harapan-harapan karyawan tersebut terpenuhi maka job security akan tinggi sedangkan apabila harapan-harapan tersebut cenderung kurang maka akan meningkatkan job insecurity. Kedua teori tersebut merupakan teori yang berkesinambungan/kontinuitas. Adapun beberapa penelitian sebelumnya yang telah mengaitkan job insecurity dan stres kerja. Seperti Bashori \& Meiyanto dalam penelitiannya juga mendapati kedua variabel berperan secara langsung yaitu job insecurity terhadap stres kerja (Bashori \& Meiyanto, 2019). Stres kerja pada pekerja tidak tetap di Korea menemukan sebanyak sepertiga dari seluruh responden mengalami kecemasan, depresi dan gejala somatik yang memerlukan perawatan kejiwaan yang disebabkan oleh adanya persepsi job insecurity/gaji yang rendah. Penelitian tersebut menemukan bahwa job insecurity yang tinggi disebabkan disparitas pendapatan, kurangnya kesempatan promosi, kurangnya penghargaan gaji yang rendah dan kurangnya sistem jaminan sosial menyebabkan dapat memperburuk tekanan kerja dan masalah kesehatan mental mereka yang menyebabkan stres kerja yang tinggi (Park dkk., 2016).

Selain faktor tersebut, terdapat faktor lain yang dapat mempengaruhi stres kerja. Menurut penelitian Utomo dkk terkait pengaruh work life balance terhadap stres kerja mendapati hasil bahwa work life balance berpengaruh negatif dan signifikan terhadap stres kerja (Utomo dkk., 2016). Penelitian yang menghubungkan work life balance dan stres kerja telah ditetapkan sebagai hubungan yang negatif, artinya semakin rendah work life balance yang dirasakan individu maka semakin tinggi tingkat stres kerja yang dialami dan semakin tinggi work life balance pada individu akan semakin rendah stres kerja yang dirasakan, hal ini dibuktikan juga dalam penelitian Khatri (2019) bahwa work life balance berhubungan langsung dengan stres kerja, hasil dari penelitian tersebut menghasilkan koefisien korelasi kedua variabel tersebut signifikan negatif (Khatri, 2019). Lalu Sigry \& Lee (2018) dalam review literature terkait work life balance menemukan banyak bukti adanya dampak seperti stres (Sirgy \& Lee, 2018).

Penyebab utama dalam hal tersebut adalah kurangnya kemampuan individu untuk membagi waktu antara kehidupan pekerjaan dengan kehidupan pribadi yang kemudian dapat mengarah stres kerja (Jaharuddin \& Zainol, 2019). Allen dkk (dalam Sirgy \& Lee, 2018) mengkategorikan dampak-dampak yang timbul dari work life balance. Kategori pertama adalah hal-hal yang berhubungan dengan sebuah 
pekerjaan, seperti komitmen organisasi, kepuasan kerja, turnover intention, dan absenteeism. Kategori kedua seperti kepuasan, kehidupan perkawinan keluarga, serta waktu luang. Kategori ketiga adalah terkait stres, seperti ketegangan, gejala somatik, kelelahan, stres keluarga serta stres kerja.

Fisher dkk (2009) menyatakan terdapat empat dimensi dari work life balance, yaitu Work Interference with Personal Life (WIPL), Personal Life Interference with Work (PLIW), Personal Life Enhancement of Work (PLEW), dan Work Enhancement of Personal Life (WEPL). WIPL dianggap sebagai pekerjaan yang kemudian dapat mengganggu individu antara lain kurangnya waktu yang dimiliki untuk mencukupi kebutuhan pribadi individu. Kebutuhan pribadi individu dapat berupa waktu bermain dengan keluarga, pasangan, ataupun ativitas sosial lainnya di luar pekerjaan. Ketika terjadi ketidakseimbangan tersebut pekerjaan yang dilakukan mungkin akan mengganggu pekerjaan yang dilakukan. Sehingga hal tersebut dapat memicu timbulnya sebuah konflik pekerjaan. Seperti hasil dari penelitian sebelumnya adanya konflik pekerjaan tersebut akan memicu munculnya stres kerja (Paramita, 2019). Sedangkan PLIW adalah kehidupan pribadi dapat mengganggu pekerjaan individu. Hal tersebut dapat terjadi ketika individu mempunyai permasalahan dalam kehidupan pribadinya hal tersebut dapat mengganggu aktivitas di pekerjaannya. Hal ini tentu dapat menggangu individu itu sendiri. Sehingga pada aspek ini konflik dari dalam kehidupan pribadi atau keluarga dapat menguras waktu, tenaga dan pikiran saat individu melakukan aktivitas pekerjaan. Ini sesuai dengan banyak dari peneliti sebelumnya seperti temuan Vickovic \& Morrow bahwa konflik dari keluarga akan mempengaruhi stres kerja (Vickovic \& Morrow, 2020). Selanjutnya dimensi PLEW adalah kehidupan pribadi dapat mempengaruhi meningkatnya kualitas atau performa pekerjaan individu. Individu yang memiliki perasaan yang bahagia dan dapat menyeimbangkan kehidupan pribadi dan pekerjaannya sehingga menurunkan resiko stres kerja. Hal ini juga sesuai dengan teori konservasi sumber daya bahwa individu yang cenderung menjaga sumber daya (kesenangan) yang dimiliki sehingga dapat menurunkan stres (Hobfoll, 1989). Dimensi keempat adalah WEPL, dimensi ini menjelaskan pekerjaan yang dialami individu dapat memberikan kualitas atau pengaruh positif terhadap kehidupan pribadi individu. Individu yang memiliki aspek ini akan cenderung mengurangi konflik di rumah dan di pekerjaan. Dengan menghindari konflik individu akan cenderung menurunkan tingkat stres kerja yang dialami karena memiliki kesenangan yang dihargai dan dijaga oleh individu (Hobfoll, 1989).

Dari paparan diatas penulis ingin mengetahui apakah job insecurity dapat mempengaruhi stres kerja pada karyawan outsourcing. Menurut Sverke dkk (2000) yaitu tipe kontrak/karyawan kontrak memiliki persepsi job insecurity lebih tinggi dibandingkan karyawan tetap Barling \& Gallagher, 1996 dan Sverke, dkk., 2000 (dalam Sverke \& Näswall, 2006). Karyawan outsourcing cenderung memiliki persepsi job insecurity lebih banyak dirasakan dalam kemungkinan kedepan yang tidak diinginkan mengenai kondisi atau perkembangan karirnya (De Witte, 2005). Selain itu, karyawan outsourcing melaporkan adanya masalah kesehatan mental dan tingkat stres yang tinggi yang dipicu karena adanya faktor tuntutan pekerjaan dan kurangnya dukungan maupun kontrol diri (Smith \& Smith, 2017). Sedangkan work life balance membutuhkan sebuah keseimbangan antara pekerjaan dengan kehidupan pribadinya dengan mampu membagi waktu antar berbagai peran yang ada (Fisher, 2001). Selain itu banyak dari peneliti sebelumnya menyatakan bahwa work life balance memiliki pengaruh yang signifikan terhadap stres kerja, sehingga penulis ingin mengetahui dimensi manakah yang lebih mempengaruhi stres kerja pada karyawan outsourcing.

Berdasarkan pemaparan di atas tersusun hipotesis-hipotesis sebagai berikut:

\section{$\mathrm{H}_{1:}$ Terdapat pengaruh job insecurity terhadap stres kerja karyawan outsourcing}

$\mathrm{H}_{2}$ : Terdapat pengaruh work interference with personal life terhadap stres kerja karyawan outsourcing

Buletin Riset Psikologi dan Kesehatan Mental (BRPKM)

2021, Vol. 1(1), 327-337 
$\mathrm{H}_{3}$ : Terdapat pengaruh personal life interference with work terhadap stres kerja karyawan outsourcing

$\mathrm{H}_{4}$ : Terdapat pengaruh personal life enhancement of work terhadap stres kerja karyawan outsourcing

$\mathrm{H}_{5}$ : Terdapat pengaruh work enhancement of personal life terhadap stres kerja karyawan outsourcing

$\mathrm{H}_{6}$ : Terdapat pengaruh job insecurity, work interference with personal life, personal life interference with work, personal life enhancement of work, dan work enhancement of personal life terhadap stres kerja karyawan outsourcing

\section{Desain Penelitian}

\section{E T ODE}

Penelitian ini menggunakan tipe penelitian kuantitatif dengan menggunakan teknik pengumpulan data berupa kuesioner. Kuesioner berisikan beberapa pertanyaan yang harus dijawab oleh subjek sesuai dengan kondisi, karakteristik, perilaku yang dirasakan. Pertanyaan tersebut berisi mengenai konsep dan atribut psikologis atau variabel penelitian (Neuman, 2014).

\section{Partisipan}

Partisipan dalam penelitian ini merupakan karyawan outsourcing berjenis kelamin laki-laki dan perempuan di Indonesia. Teknik sampling yang digunakan adalah convenience sampling dalam non probability sampling. Teknik ini digunakan karena tidak diketahui jumlah seluruh populasi dan sampel dapat pada siapa saja yang mudah dijangkau atau tersedia untuk kemudian menjadi partisipan penelitian. Seluruh partisipan yang berpartisipasi dalam penelitian ini berjumlah 83 orang. $\left(M_{\mathrm{usia}}=35,83 ; 86,7\right.$ persen laki-laki). Mayoritas usia partisipan paling banyak 31-40 tahun (42,1\%).

\section{Pengukuran}

Pengukuran yang digunakan menggunakan tiga alat ukur sebagai berikut. Pengukuran job insecurity menggunakan job insecurity scale sebanyak 4 aitem dari De Witte (2000) (dalam Saraswati, 2017) dan memiliki reliabilitas $(\alpha=.95)$. Pengukuran work life balance menggunakan skala dari Fisher dkk (2009) (dalam Prameswari, 2018) terdiri dari 17 aitem dan memiliki reliabilitas $(\alpha=.91)$. Pengukuran stres kerja sebanyak 9 aitem dari De Bruin \& Taylor (2005) (dalam Kristianto, 2017) memiliki reliabilitas $(\alpha=.89)$. Pada skala job insecurity dan work life balance menggunakan 4 skala likert yaitu skor 1 adalah tidak pernah/sangat tidak setuju hingga skor 4 adalah selalu/sangat setuju. Pada skala stres kerja menggunakan 4 skala likert dengan skor 1 adalah tidak pernah/sangat tidak setuju hingga skor 4 adalah selalu/sangat setuju. Ketiga alat ukur tersebut menggunakan content validity oleh professional judgement masing-masing dalam pengujian alat ukurnya.

\section{Analisis Data}

Teknik analisis data pada penelitian ini menggunakan uji analisis regresi linear berganda. Untuk melakukan uji analisis regresi linear berganda, perlu dilakukan beberapa uji asumsi. Uji asumsi pertama adalah uji normalitas residual, dari uji tersebut Plot yang terlihat menunjukkan tidak ada penyimpangan distribusi yang tidak normal. Sehingga, distribusi data bisa dianggap normal. Kedua adalah uji linearitas,

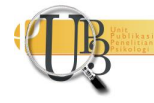


dari uji tersebut kedua variabel independen adalah linear. Ketiga dilakukan uji homokedastisitas, dari uji tersebut scatterplot tidak mengalami heterokedastisitas. Keempat adalah uji multikolinearitas, dari uji tersebut didapatkan hasil bahwa kedua variabel independen dinyatakan tidak berhubungan satu sama lain. Setelah uji asumsi terpenuhi, selanjutnya melakukan uji analisis regresi linear berganda dengan menggunakan aplikasi IBM SPSS Statistic 22 for Windows.

\section{HAS IL PENELITIAN}

Hasil analisis deskriptif menunjukkan tingkat stres kerja pada karyawan outsourcing mayoritas rendah yaitu sebanyak 70 orang, pada tingkat sedang sebanyak 9 orang, dan pada tingkat tinggi sebanyak 4 orang. Pada variabel job insecurity mayoritas pada tingkat sedang yaitu sebanyak 71 orang, pada tingkat rendah sebanyak 2 orang dan pada tingkat tinggi sebanyak 10 orang. Pada variabel work life balance mayoritas pada tingkat sedang sebanyak 66 orang, pada tingkat tinggi sebanyak 16 orang sedangkan pada tingkat rendah sebanyak 1 orang. Kategorisasi tersebut didasarkan dari rumus milik Azwar (2011).

Hasil uji parsial dari analisis regresi linear berganda menunjukkan bahwa job insecurity memiliki nilai signifikansi 0,877. Selanjutnya dimensi work interference with personal life memiliki nilai signifikansi sebesar 0,010. Dimensi personal life interference with work memiliki nilai signifikansi sebesar 0,793. Pada dimensi personal life enhancement of work memiliki nilai signifikansi 0,046. Dari dimensi work enhancement of personal life memiliki nilai signifikansi 0,759. Berdasarkan hasil uji analisis regresi linear berganda secara bersama-sama variabel job insecurity dan keempat dimensi work life balance menunjukkan nilai signifikansi 0,001. Besar pengaruh variabel independen nilai R Square sebesar 0,226 atau sebesar 22,6\% stres kerja yang dapat dipengaruhi dengan Job Insecurity dan keempat dimensi Work Life Balance. Sedangkan 77,4\% sisanya dijelaskan oleh variabel lainnya yang tidak diteliti pada penelitian ini.

\section{I S K U S I}

Penelitian ini memiliki tujuan untuk mengetahui adakah pengaruh job insecurity dan work life balance terhadap stres kerja pada karyawan outsourcing. Dari uji analisis regresi linear berganda mendapatkan hasil bahwa terdapat pengaruh yang signifikan dari job insecurity dan keempat dimensi work life balance terhadap stres kerja pada karyawan outsourcing. Hal ini dibuktikan oleh hasil signifikansi uji analisis regresi linear berganda yaitu sebesar 0,001 yang mana nilai tersebut kurang dari 0,05. Pada hasil analisis di atas terdapat nilai R Square sebesar 0,226 yang artinya pengaruh job insecurity dan work life balance secara bersama-sama memiliki pengaruh sebanyak $22,6 \%$ terhadap stres kerja pada karyawan outsourcing.

Pada penelitian ini job insecurity tidak mempunyai pengaruh terhadap stres kerja. Hal ini dibuktikan nilai signifikansi pada variabel job insecurity sebesar 0,877 . Tingkat job insecurity yang dialami oleh karyawan outsourcing yang menjadi subjek penelitian ini mayoritas pada taraf sedang yaitu sebanyak 71 responden atau sebanyak 85,5\%. Sedangkan pada kategori tinggi sebanyak 10 responden atau $12 \%$. Tingkat job insecurity tersebut tidak mengganggu bagi individu yang mengalaminya. Penelitian yang dilakukan oleh Bashori \& Meiyanto mendapatkan hasil bahwa job insecurity memiliki pengaruh yang signifikan langsung terhadap stres kerja. Berbeda dengan hasil tersebut pada penelitian ini job insecurity tidak memiliki pengaruh terhadap stres kerja. Sverke, dkk (2006) menjelaskan bahwa job insecurity lebih cenderung dirasakan oleh laki-laki dari pada perempuan. Hal ini dijelaskan oleh pendapat bahwa 
nilai-nilai tradisional dapat mendorong laki-laki untuk mengalami tingkat ketidakamanan kerja yang lebih tinggi daripada perempuan, karena peran tradisional mengharuskan laki-laki untuk menjadi pencari nafkah keluarga. Meskipun sampel didominasi oleh laki-laki yaitu sebanyak 86,7\% job insecurity yang dirasakan tidak dapat mempengaruhi stres kerja. Hal ini dapat dijelaskan melalui data demografis pada sampel penelitian ini. Bahwa ternyata peran gender dapat mempengaruhi tingkat stres kerja. Pada penelitian Nasrani \& Purnawati (2016) bidang kedokteran dan fisiologi menjelaskan hasil penelitiannya bahwa laki-laki umumnya menikmati adanya konflik yang dirasakan bahkan menganggap konflik sebagai dorogan untuk memicu pada hal-hal yang positif. Sedangkan otak yang ada pada perempuan memiliki mekanisme kewaspadaan yang negatif terhadap adanya konflik dan stres yang kemudian dapat memicu hormon negatif sehingga memunculkan gelisah, rasa ketakutan dan stres. Hasil penelitian tersebut mendapati perbedaan tingkat stres laki-laki jauh lebih rendah yaitu 4,9\% dan perempuan sebesar 50,3\% (Nasrani \& Purnawati, 2016). Sehingga meskipun terjadi kekhawatiran dalam kelangsungan pekerjaan individu pada populasi penelitian ini dapat memicu kepada hal-hal positif dan tidak merasakan stres.

Occupational health psychology mengidentifikasi sejumlah besar pemicu stres kerja, dimana job insecurity hanyalah salah satunya, Tidak adanya pengaruh job insecurity terhadap stres kerja ini mendukung penelitian De Witte (1999) penelitian tersebut membandingkan pengaruh job insecurity dengan penyebab stres lainnya, hasilnya menunjukkan bahwa job insecurity adalah salah satu faktor yang paling tidak penting di antara penyebab stres (De Witte, 2005). Selain itu penelitian ini juga mendukung hasil dari penelitian Rikardo \& Susanti bahwa dalam penelitiannya tidak terdapat pengaruh signifikan antara job insecurity terhadap stres kerja di PT Garda Total Security Padang dengan artian bahwa karyawan yang mempunyai job insecurity tidak akan memengaruhi tingkat stres karyawan di PT Garda Total Security Padang. Dalam hasil analisis penelitian tersebut, tingkat job insecurity cenderung rendah (Rikardo \& Susanti, 2012).

Pada variabel work life balance dalam penelitian dapat dijelaskan dari masing-masing dimensinya dalam mempengaruhi stres kerja pada populasi penelitian ini yaitu karyawan outsourcing. Secara parsial aspek personal life interference with work (PLIW) memiliki nilai signifikansi 0,793 sehingga dapat dikatakan bahwa aspek tersebut tidak memiliki pengaruh yang signifikan terhadap stres kerja. PLIW dapat diartikan sebagai kehidupan pribadi individu dapat mengganggu pekerjaan. Dalam melaksanakan sebuah pekerjaan beberapa karyawan cenderung tidak ingin membawa permasalahan di rumah ke tempat kerja. Hal ini juga dijelaskan oleh beberapa responden dalam penelitian ini saat melakukan interaksi informal. Mereka menjelaskan apapun permasalahannya sebisa mungkin tidak membawa permasalahan tersebut ke tempat kerja karena resiko tugas yang berat akan dapat membahayakan jika terus terbawa dalam permasalahan tersebut. Sehingga karyawan ingin memisahkan urusan pribadi dengan urusan pekerjaan. Namun, hal ini tentu tidak semua orang bisa melakukannya. Fisher dkk (2009) juga telah menjelaskan bahwa aspek ini tidak memiliki kaitan dengan stres kerja. pada aspek personal life interference with work (PLIW) lebih dikaitkan pengaruhnya terhadap kepuasan kerja.

Pada aspek work enhancement of personal life (WEPL) memiliki nilai signifikansi 0,759 sehingga pada aspek ini juga tidak dapat mempengaruhi tingkat stres kerja pada populasi penelitian ini. WEPL dapat didefinisikan sebagai pekerjaan yang dialami individu dapat memberikan kualitas atau pengaruh positif terhadap kehidupan pribadi individu sehingga diharapkan hal ini dapat mempengaruhi atau menurunkan tingkat stres kerja. Namun, konflik dalam permasalahan kehidupan pribadi individu mungkin sangatlah kompleks dan bermacam-macam jenisnya, sehingga pekerjaan yang menyenangkan belum tentu dapat membawa dampak positif terhadap kehidupan pribadi. Hal ini sesuai dengan yang disebutkan oleh Fisher dkk (2009) bahwa penelitian sebelumnya menyatakan penyebab stres lebih banyak dipengaruhi oleh konflik yang terjadi di pekerjaan yang kemudian mempengaruhi keluarga dan bukan sebaliknya Frone dkk 1992 (dalam Fisher dkk., 2009).

Buletin Riset Psikologi dan Kesehatan Mental (BRPKM)

2021, Vol. 1(1), 327-337 
Pada dimensi Work Interference with Personal Life (WIPL) memiliki nilai signifikansi sebesar 0,010 yang berarti bahwa dimensi tersebut memiliki pengaruh yang signifikan terhadap stres kerja. WIPL didefiniskan sebagai pekerjaan yang dapat mengganggu kehidupan pribadi individu. Pekerjaan yang kemudian dapat mengganggu individu antara lain kurangnya waktu yang dimiliki untuk mencukupi kebutuhan pribadi individu. Kebutuhan pribadi individu dapat berupa waktu bermain dengan keluarga, pasangan, ataupun ativitas sosial lainnya di luar pekerjaan. Ketika terjadi ketidakseimbangan tersebut pekerjaan yang dilakukan mungkin akan mengganggu pekerjaan yang dilakukan. Sehingga hal tersebut dapat memicu timbulnya sebuah konflik pekerjaan dan konflik pekerjaan akan dapat memberi pengaruh terhadap stres pekerjaan (Paramita, 2019). Hal ini sesuai dengan teori peran oleh Kahn dkk (1964) dan Hobfoll (1989) bahwa pekerjaan mengganggu kehidupan pribadi individu (WIPL) merupakan pemicu dari stres kerja (Fisher dkk., 2009).

Selain itu dimensi Personal Life Enhancement of Work memiliki nilai signifikansi sebesar 0,046 sehingga dimensi tersebut juga memiliki pengaruh yang signifikan terhadap stres kerja. PLEW didefinisikan sebagai kehidupan pribadi individu yang dapat memberi nilai positif terhadap pekerjaan. Saat kehidupan pribadi individu menyenangkan, hal tersebut dapat membuat individu bersemangat dan akan mempengaruhi pekerjaan menjadi lebih menyenangkan. Dengan demikian individu memiliki perasaan yang bahagia dan dapat menyeimbangkan kehidupan pribadi dan pekerjaannya sehingga menurunkan resiko stres kerja. Hal ini juga sesuai dengan teori konservasi sumber daya bahwa individu yang cenderung menjaga sumber daya (kesenangan) yang dimiliki sehingga dapat menurunkan stres (Hobfoll, 1989). Selain itu menurut Frone dkk (1992) kehidupan pribadi memang akan lebih memiliki pengaruh terhadap pekerjaan Frone dkk 1992 (dalam Fisher dkk., 2009).

Dari hasil uji analisis regresi linear berganda variabel job insecurity dan keempat dimensi work life balance memiliki pengaruh yang signifikan terhadap stres kerja pada karyawan outsourcing. Selain maraknya isu tentang tingginya job insecurity yang dirasakan karyawan outsourcing ataupun karyawan tipe kontrak pada penelitian ini peneliti juga meninjau beberapa data penelitian yang menunjukkan adanya penyebab stres yang karena tingginya intensitas serta tuntutan kerja karyawan outsourcing membuat peneliti ingin mengetahui tingkat work life balance pada karyawan outsourcing di Indonesia dan apakah hal tersebut akan mempengaruhi stres kerja. Banyak dari temuan sebelumnya yang memiliki hasil serupa dengan hasil penelitian ini, sebelumnya para peneliti menyatakan bahwa work life balance memiliki pengaruh yang signifikan terhadap stres kerja. Seperti temuan dari Balkan (2014) bahwa work life balance memiliki pengaruh yang signifikan terhadap stres kerja dan kinerja individu. (Balkan, 2014). Namun, pada penelitian ini peneliti ingin mengetahui pada aspek/dimensi manakah yang signifikan dalam mempengaruhi stres kerja pada karyawan outsourcing.

Selain itu wawancara juga dilakukan dengan salah satu karyawan outsourcing langsung yang menjadi subjek dalam penelitian ini. Pada wawancara tersebut peneliti ingin mengetahui kinerja pada karyawan outsourcing perusahaan pupuk di Gresik. Kinerja pada karyawan outsourcing tersebut cenderung baik meskipun tingkat stres yang dirasakan mungkin cenderung sedang. Hal tersebut dibuktikan bahwa jika kinerja baik karywan outsourcing akan terus diperpanjang masa kerjanya, apabila terdapat penurunan kinerja akan mendapat peringatan serta pemutusan hubungan kerja. Stres yang dialami karyawan outsourcing menurut hasil dari wawancara tersebut lebih banyak pada bidang produksi karena APD (Alat Pelindung Diri) yang sudah tidak layak pakai namun pembaharuan cenderung sedikit. Selain itu kurangnya jaminan keselamatan kerja juga menjadi hal yang menjadi perhatian bagi karyawan outsourcing itu sendiri. Meski demikian kinerja outsourcing pada perusahaan tersebut masih tergolong baik karena sedikit dari mereka yang mendapat peringatan oleh perusahaan itu sendiri. Hal tersebut selaras dengan penjelasan sebelumnya bahwa fenomena stres kini memang telah menjadi bagian hidup yang tidak bisa dipisahkan (Kupriyanov dkk., 2014). Stres kerja memiliki dampak yang baik terhadap kinerja apabila stres tidak melampaui batas maksimal. Sedangkan stres yang berdampak negatif adalah

Buletin Riset Psikologi dan Kesehatan Mental (BRPKM)

2021, Vol. 1(1), 327-337 
saat stres yang telah melebihi kurva atau batas maksimal (Le Fevre dkk., 2003). Meskipun demikian, stres kerja tetap harus diwaspadai karena juga memiliki dampak-dampak yang dapat merugikan bagi organisasi maupun individu itu sendiri.

\section{S I M P U L A N}

Berdasarkan analisis data pada penelitian ini mendapatkan hasil bahwa variabel job insecurity tidak memiliki pengaruh signifikan terhadap stres kerja maka $\mathrm{H}_{1}$ ditolak. Selanjutnya dimensi WIPL memiliki pengaruh yang signifikan terhadap stres kerja maka $\mathrm{H}_{2}$ diterima. Pada dimensi PLIW tidak memiliki pengaruh yang signifikan terhadap stres kerja maka $\mathrm{H}_{3}$ ditolak. Untuk dimensi PLEW memiliki pengaruh yang signifikan terhadap stres kerja maka $\mathrm{H}_{4}$ diterima. Untuk dimensi WEPL tidak memiliki pengaruh yang signifikan terhadap stres kerja maka $\mathrm{H}_{5}$ ditolak. Namun secara bersama-sama yaitu job insecurity, WIPL, PLIW, PLEW, dan WEPL memiliki pengaruh yang signifikan terhadap stres kerja maka $\mathrm{H}_{6}$ diterima.

Saran yang ditujukan bagi peneliti selanjutnya adalah didasarkan dari hasil wawancara informal banyak karyawan outsourcing pada perusahaan industri memiliki permasalahan pada keselamatan kerja. Bagi peneliti selanjutnya agar meneliti terkait permasalahan-permasalahan lain pada karyawan outsourcing seperti keselamatan kerja pada karyawan outsourcing di perusahaan-perusahaan industri. Bagi karyawan outsourcing yang merasakan stres agar dapat mengelola pemicu stres dengan memberikan pemaknaan positif bahwa stres perlu dilewati untuk memperoleh tujuan-tujuan tertentu. Sehingga stres kerja dapat memiliki dampak yang positif untuk kinerja. Selanjutnya agar menciptakan lingkungan kerja yang nyaman dan menjaga hubungan baik kantar rekan kerja agar meminimalisir permasalahan pekerjaan yang dapat mengganggu kehidupan pribadi, menyisihkan sebagian waktu untuk kehidupan pribadi agar memiliki kepuasan di luar pekerjaan dan memberikan rasa semangat untuk kembali melakukan aktivitas pekerjaan. Bagi organisasi agar tetap memperhatikan keselamatan kerja seperti Alat Pelindung Diri (APD) untuk meningkatkan jaminan keselamatan kerja pada karyawan outsourcing.

\section{U C A P A N T ER I MAKASIH}

Terima kasih penulis ucapkan kepada Allah SWT, keluarga, teman-teman serta partisipan yang bersedia meluangkan waktu dalam pengisian kuesioner penelitian serta pihak-pihak lain yang membantu dalam penyelesaian penelitian ini.

\section{DEKLARASI POTENSI TERJADINYAKONFLIKKEPENTINGAN}

Mochammad Rizal Ramdhan dan Fajrianthi tidak bekerja, menjadi konsultan, memiliki saham, atau menerima dana dari perusahaan atau organisasi manapun yang mungkin akan mengambil untung dari diterbitkannya naskah ini.

\section{P US T A KA ACUAN}

Balkan, O. (2014). Work-Life Balance, Job Stress and Individual Performance: An Application Author Detail . Onur Balkan -Asst. Proffesor University of Turkish Aviation Association Turkey. Work-Life Balance, Job Stress and Individual Performance: An Application Author Detail . Onur Balkan -Asst. Proffesor University of Turkish Aviation Association Turkey, 3, 38-46. 
Bashori, M. F., \& Meiyanto, I. S. (2019). Peran Job Insecurity terhadap Stres Kerja dengan Moderator Religiusitas. Gadjah Mada Journal of Psychology (GamaJoP), 3(1), 25. https://doi.org/10.22146/gamajop.42396

Bienertova-Vasku, J., Lenart, P., \& Scheringer, M. (2020). Eustress and Distress: Neither Good Nor Bad, but Rather the Same? BioEssays, 42(7), 1-5. https://doi.org/10.1002/bies.201900238

De Bruin, G. P. (2006). The dimensionality of the general work stress scale: A hierarchical exploratory factor analysis. SA Journal of Industrial Psychology. https://doi.org/10.4102/sajip.v32i4.250

De Bruin, G. P., \& Taylor, N. (2005). Development of the sources of work stress inventory. South African Journal of Psychology, 35(4), 748-765. https://doi.org/10.1177/008124630503500408

De Witte, H. (2005). Job insecurity: Review of the international literature on definitions, prevalence, antecedents and consequences. SA Journal of Industrial Psychology, 31(4). https://doi.org/10.4102/sajip.v31i4.200

Fisher, G. G., Bulger, C. A., \& Smith, C. S. (2009). Beyond Work and Family: A Measure of Work/Nonwork Interference and Enhancement. Journal of Occupational Health Psychology, 14(4), 441-456. https://doi.org/10.1037/a0016737

Gadzella, B., Baloglu, M., Masten, W., \& Wang, Q. (2012). Evaluation of the Student Life-Stress InventoryRevised. Journal of Instructional Psychology, 39(2), 82.

Habibi, J., \& Jefri. (2018). Analisis Faktor Risiko Stres Kerja Pada Pekerja Di Unit Produksi Pt. Borneo Melintang Buana Export. Journal of Nursing and Public Health, 6(2), 50-59.

Hobfoll, S. E. (1989). Conservation of Resources: A New Attempt at Conceptualizing Stress. American Psychologist, 44(3), 513-524. https://doi.org/10.1037/0003-066X.44.3.513

Hoboubi, N., Choobineh, A., Kamari Ghanavati, F., Keshavarzi, S., \& Akbar Hosseini, A. (2017). The Impact of Job Stress and Job Satisfaction on Workforce Productivity in an Iranian Petrochemical Industry. Safety and Health at Work, 8(1), 67-71. https://doi.org/10.1016/j.shaw.2016.07.002

Jaharuddin, N. S., \& Zainol, L. N. (2019). The Impact of Work-Life Balance on Job Engagement and Turnover Intention. The South East Asian Journal of Management, 13(1). https://doi.org/10.21002/seam.v13i1.10912

Khatri, D. K. (2019). A Study on Relationship between Work Life Balance and Job Stress : A Case Study of College Teachers in Rajasthan (India ). 9(6), 5-8. https://doi.org/10.9790/7388-0906030508

Kristianto, D. Y. (2017). Hubungan antara Work Stress dengan Workplace Incivility Behavior pada Karyawan Sales di Perusahaan Multimedia X Surabaya.

Kupriyanov, R. V, Sholokhov, M. A., Kupriyanov, R., \& Zhdanov, R. (2014). The Eustress Concept: Problems and Outlooks. World Journal of Medical Sciences, 11(2), 179-185. https://doi.org/10.5829/idosi.wjms.2014.11.2.8433

Le Fevre, M., Matheny, J., \& Kolt, G. S. (2003). Eustress, distress, and interpretation in occupational stress. $\begin{array}{lllll}\text { Journal of } & \text { Managerial } & \text { Psychology, } & \text { 18(7-8), } & \text { 726-744. }\end{array}$

Buletin Riset Psikologi dan Kesehatan Mental (BRPKM)

2021, Vol. 1(1), 327-337 
https://doi.org/10.1108/02683940310502412

Liu, S., \& Onwuegbuzie, A. J. (2012). Chinese teachers' work stress and their turnover intention. International Journal of Educational Research, 53, 160-170. https://doi.org/10.1016/j.ijer.2012.03.006

Nasrani, L., \& Purnawati, S. (2016). Nasrani \& Purnawati.

Padma, V., Anand, N. N., Gurukul, S. M. G. S., Javid, S. M. A. S. M., Prasad, A., \& Arun, S. (2015). Health problems and stress in Information Technology and Business Process Outsourcing employees. Journal of Pharmacy and Bioallied Sciences, 7(April), S9-S13. https://doi.org/10.4103/09757406.155764

Paramita, P. D. (2019). PENGARUH KONFLIK KERJA DAN BEBAN KERJA TERHADAP STRES KERJA YANG BERDAMPAK PADA PRODUKTIVITAS KERJA KARYAWAN [STUDI KASUS DI PT. LA LUNA SEMARANG) Patricia. Journal of Chemical Information and Modeling, 53(9), 1689-1699.

Park, S. K., Rhee, M. K., \& Barak, M. M. (2016). Job stress and mental health among nonregular workers in Korea: What dimensions of job stress are associated with mental health? Archives of Environmental and Occupational Health, 71(2), 111-118. https://doi.org/10.1080/19338244.2014.997381

Prameswari, G. A. (2018). Pengaruh Karakteristik Pekerjaan terhadap Keterikatan Kerja Karyawan Generasi $Y$ melalui Keseimbangan Kehidupan-Kerja Sebagai Mediator. 4(4), 107-112. http://dx.doi.org/10.1016/j.jana.2010.11.008\%0Ahttps://doi.org/10.1016/j.ijid.2018.10.009

Puspita Sari, N. O., Wahyuni, I., \& Ekawati, E. (2016). Pengaruh Stres Kerja Terhadap Kinerja Karyawan Outsourcing Bagian Feed Pt. X. Jurnal Kesehatan Masyarakat (e-Journal), 4(4), 722-729.

Saraswati, A. N. A. (2017). Pengaruh Job Insecurity terhadap Kinerja Karyawan pada PT X. In Tesis.

Sirgy, M. J., \& Lee, D. J. (2018). Work-Life Balance: an Integrative Review. Applied Research in Quality of Life, 13(1), 229-254. https://doi.org/10.1007/s11482-017-9509-8

Smith, A., \& Smith, H. (2017). An International Survey of the Wellbeing of Employees in the Business Process Outsourcing Industry. Psychology, 08(01), 160-167. https://doi.org/10.4236/psych.2017.81010

Susanti, T. (2012). Pengaruh Job Insecurity dan Beban Kerja Terhadap Stres Kerja pada PT GARDA TOTAL SECURITY PADANG. Sekolah Tinggi Ilmu Eknomi “KBP,” 66, 37-39.

Sverke, M., \& Näswall, K. (2006). Job insecurity_a literature review(2006).pdf. 1.

Utomo, C., \& Djastuti, I. (n.d.). Terhadap Stres Kerja Yang Berimplikasi Pada Kinerja Pegawai ( Studi Pada Bpk Perwakilan Provinsi Jawa Tengah ). Pengaruh kesimbangan kehidupan-kerja terhadap stres kerja yang berimplikasi pada kinerja pegawai, 1-20.

Vickovic, S. G., \& Morrow, W. J. (2020). Examining the Influence of Work-Family Conflict on Job Stress, Job Satisfaction, and Organizational Commitment Among Correctional Officers. Criminal Justice Review, 45(1), 5-25. https://doi.org/10.1177/0734016819863099

Buletin Riset Psikologi dan Kesehatan Mental (BRPKM)

2021, Vol. 1(1), 327-337 